\title{
PENERAPAN NILAI-NILAI PANCASILA DALAM PELAKSANAAN UPACARA ADAT PURUNG TA KADONGA RATU PADA MASYARAKAT DESA MAKATAKERI KECAMATAN KATIKUTANA KABUPATEN SUMBA TENGAH PROVINSI NUSA TENGGARA TIMUR (NNT)
}

\author{
I Made Sila \\ Program Studi Pendidikan Pancasila dan Kewarganegaraan, Fakultas Keguruan Dan Ilmu Pendidikan \\ Universitas Dwijendra Denpasar \\ email : madesila@undwi.ac.id
}

\section{Made Purana}

Program Studi Pendidikan Pancasila dan Kewarganegaraan, Fakultas Keguruan Dan Ilmu Pendidikan Universitas Dwijendra Denpasar email: purana@undwi.ac.id

\section{Arni Rambu Bauru Awa}

Program Studi Pendidikan Pancasila dan Kewarganegaraan, Fakultas Keguruan Dan Ilmu Pendidikan Universitas Dwijendra Denpasar email : arnirambu@gmail.com

\begin{abstract}
Abstrak
Purung Ta Kadonga Ratu (Turun di Lemba Imam) merupakan ritual adat yang dilakukan masyarakat Sumba setiap tahun sekali untuk memperingati para leluhur yang dianggap memiliki kekuatan magis dan dapat memprediksi kesuburan hasil pertanian masyarakat. Ritual adat Purung Ta Kadonga Ratu (Turun di Lemba Imam) sebelum dilaksanakan terlebih dahulu dilakukan acara pemotongan kerbau jantan yang bahasa adatnya "Haka Raja Rewa"yang artinya ukuran tanduk kerbau yang akan dipotong untuk memberikan persembahan kepada leluhur. Acara ritual adat Purung ta Kadonga Ratu (Turun di Lemba Imam) di lakukan di sebuah tempat yang tinggi yang dirasa cocok oleh tua adat ("Ama Walu Adung, Ina Walu Kerung") yang dianggap sebagai kepala suku atau penanggung jawab untuk semua suku dalam melakukan ritual. Tempat dilakukan ritual adat Purung ta Kadonga Ratu (Turun di Lemba Imam) diberi nama"Laitarung". Berdasarkan latar belakang tersebut, rumusan masalnya adalah pelaksanaan Nilai-nilai Pancasila apa saja yang terkandung dalam upacara adat Purung Ta Kadonga Ratu pada masyarakat Desa Makatakeri Kecamatan Katikutana Kabupaten Sumba Tengah, Bagaimana proses pelaksanaan Upacara Adat Purung ta Kadonga Ratu pada kehidupan masyarakat sehari-hari di Desa Makatakeri Kecamatan Katikutana Kabupaten Sumba Tengah. Tujuan penelitian ini adalah untuk mengetahui lebih dalam tentang Penerapan Nilai-Nilai Pancasila Dalam Pelaksanaan Upacara Adat Purung Ta Kadonga Ratu Pada Masyarakat Desa Makatakeri Kecamatan Katikutana Kabupaten Sumba Tengah, Teknik pengumpulan data yang digunakan pada penelitian ini adalah Teknik wawancara, teknik observasi, teknik dokumentasi Metode atau teknik yang digunakan untuk menganalisi data adalah metode deskriptif kualitatif. Hasil Penelitian menyatakan bahwa Upacara adat ini dilakukan dengan mengacungkan dua tombak pusaka keramat yang panjangnya kurang lebih 7 meter yang diacungkan ke langit untuk menjebol bendungan di langit untuk mendatangkan atau menurunkan hujan. Kedua tombak keramaat itu yakni Loda Pari dan Mehang Karaga. Apabila dalam lomba mengangkat tombak yang mengarah kelangit dan yang menang pertama adalah "Nibu loda pari" maka diprediksikan hasil pertanian subur dan musim hujan juga beraturan yang bahasa adatnya "hawewanaga pungina, kabobunaga ratina". Kalau "nibu mehang karaga" yang menang pertama maka diprediksikan hasil pertanian tidak subur dan akan ada kelaparan besar melanda pulau Sumba yang bahasa adatnya"danakerimawaka tuwa danahimawaka watu, nyeka pagaliparawigika waiga bakukapata wewi wawi bakukanuka wewi kauki".
\end{abstract}

Kata Kunci: Penerapan Nilai-Nilai Pancasila, Upacara Adat Purung Ta Kadonga Ratu 


\begin{abstract}
Purung Ta Kadonga Ratu (Descended in Lemba Imam) is a traditional ritual that is carried out by the Sumba people every year to commemorate the ancestors who are considered to have magical powers and can predict the fertility of the agricultural produce of the community. Purung Ta Kadonga Ratu's traditional ritual (Going down at Lemba Imam) before the male buffalo slaughtering ceremony for which the customary language is "Haka Raja Rewa" means the size of the buffalo horn that will be cut to make offerings to the ancestors. Purung ta Kadonga Ratu (Down in Lemba Imam) traditional rituals are held in a high place that is considered suitable by the traditional elders ("Ama Walu Adung, Ina Walu Kerung") who are considered as tribal chiefs or responsible for all tribes in carrying out ritual. The place where Purung ta Kadonga Ratu (Descended in Lemba Imam) traditional ritual is named "Laitarung". Based on this background, the mass formulation is the implementation of any Pancasila Values contained in the Purung Ta Kadonga Ratu traditional ceremony in the people of Makatakeri Village, Katikutana Subdistrict, Central Sumba Regency, How is the process of implementing Purung ta Kadonga Ratu Traditional Ceremony in people's daily lives $\neg$ in Makatakeri Village, Katikutana District, Central Sumba Regency. The purpose of this study was to find out more about the Implementation of Pancasila Values in the Implementation of the Purung Ta Kadonga Ratu Ceremony in the Makatakeri Village Community Katikutana Subdistrict, Central Sumba, Data collection techniques used in this study were interview techniques, observation techniques, documentation techniques Method or the technique used to analyze data is a qualitative descriptive method. The results of the study stated that this traditional ceremony was carried out by brandishing two sacred heirloom spears that were approximately 7 meters in length that were stretched toward the sky to break down dams in the sky to bring or bring down rain. The two religious spears were Loda Pari and Mehang Karaga. If in the race to lift the spear that leads to the sky and the first winner is "Nibu loda pari" then it is predicted that fertile agricultural products and the rainy season are also regular with the traditional language "hawewanaga pungina, kabobunaga ratina". If "nibu mehang karaga" wins first, it is predicted that agricultural products are infertile and there will be a huge famine in the island of Sumba, the customary language "danakerimawaka tuwa and Ibrahimawaka watu, wiping pagaliparawigika waiga bakukapata wewi wawi bakukanuka wewi kauki".
\end{abstract}

Keywords: Implementation of Pancasila Values, Purung Ta Kadonga Ratu Traditional Ceremony

\section{PENDAhuluan}

Berbicara tentang pancasila, tentu berkaitan dengan Nilai-nilai pancasila, serta pengalaman-pengalaman dalam kehidupan berbangsa dan bernegara, serta nilai-nilai pancasila memiliki makna yang mendalam baikdari segi sejarah pembentukan pengamalan. Pancasila adalah lambang Negara yang juga landasannya untuk menuju cita-cita tersebut. Dengan perkembangan teknologi yang tak lain adalah globalisasi telah mengikis nilai-nilai tersebut dalam kehidupan masyarakat. Sehingga mengakibatkan ketidaktahuan masyarakat Indonesia terhadap nilai-nilai dan dasar Negara dan menanamkan pemikiran bahwa nilai-nilai dan pengalaman-pengalaman pancasila.
Bangsa Indonesia adalah bangsa yang multikultural sehingga menciptakan beranekaragam kebudayaan yang unik dan memiliki ciri khas tersendiri sesuai dengan daerah dan etnis masing-masing. Kebudayaan yang kita miliki selain beranekaragam dan membanggakan juga dapat memberikan citra yang baik dari bangsa lain karena kebudayaan yang dimiliki bukanlah semata-mata warnawarni dan simbol perbedaan, melainkan juga kekayaan sekaligus modal bangsa kita untuk menjadi bangsa besar. Sebab, kebudayaan lokal tersebut menyimpan pengalaman, sejarah, jejakjejak kreativitas dan peradaban tertentu yang memiliki nilai-nilai luhur. 
Keragaman budaya di Indonesia adalah sesuatu yang tidak dapat dipungkiri keberadaannya. Dalam konteks pemahaman masyarakat majemuk, selain kebudayaan kelompok suku bangsa, masyarakat Indonesia juga terdiri dari berbagai kebudayaan daerah bersifat kewilayahan yang merupakan pertemuan dari berbagai kebudayaan kelompok suku bangsa yang ada didaerah tersebut. Bisa dikatakan bahwa Indonesia adalah salah satu negara dengan tingkat keaneragaman budaya atau tingkat heterogenitasnya yang tinggi. Tidak saja keanekaragaman budaya kelompok suku bangsa namun juga keanekaragaman budaya dalam konteks peradaban, tradisional hingga ke modern, dan kewilayahan.

Sebagai negara kepulauan, hampir seluruh daerah di Indonesia memiliki kebudayaan tersendiri yang tentunya memiliki nilai-nilai atau norma-norma tertentu yang senantiasa diwariskan, ditafsirkan dan dilaksanakan seiring dengan proses perubahan sosial kemasyarakatan. Nilai-nilai tersebut menyatu dalam kehidupan masyarakat setempat, memberi landasan yang kuat bagi keberlangsungan hidupnya, menjadikan hubungan antara manusia dengan alam menjadi lebih selaras dan harmonis, serta dijadikan sebagai sarana dalam membangun karakter seseorang.

Manusia merupakan makluk ciptaan Tuhan yang dibekali dengan akal budi dibandingkan dengan makluk ciptaan lainnya. Manusia memiliki jiwa, rasa dan karsa untuk hidup berkelompok dan membentuk sebuah komunitas yang dinamakan masyarakat. Masyarakat dibelahan dunia manapun selalu ditandai dengan kebudayaannya masing-masing sebagai ciri khas serta eksistensi dari masyarakat itu sendiri. Ketika seseorang berusaha berkomunikasi dengan orang-orang yang berbeda budaya dan menyesuaikan perbedaan yang membuktikan bahwa budaya itu dipelajari. Budaya adalah suatu pola hidup menyeluruh. Budaya bersifat kompleks, abstrak dan luas. Banyak aspek budaya turut menentukan perilaku komunikatif.

Masyarakat Nusa Tenggara Timur (NTT) terbagi berbagai Kabupaten-Kabupaten yang memiliki budaya dan ciri khas dan keragaman budaya yang berupa simbol-simbol dan nilainilai sebagai hasil karya seni dari perilaku manusia. Dari berbagai keragaman budaya yang ada disetiap Kabupaten di NTT maka terdapat pada Kabupaten Sumba Tengah lebih khususnya di Desa Makatakeri yang memiliki budaya Purungu Ta Kadongga Ratu sebagai salah satu contoh budaya yang ada di NTT.

Anakalang adalah salah satu Kabupaten di Sumba Tengah yaitu Ibukota Waibakul, Provinsi Nusa Tenggara Timur. Di daerah ini terdapat suatu ritual adat warisan nenek moyang yang turun-temurun masih tetap dilaksanakan sampai sekarang. Upacara adat dijunjung tinggi oleh masyarakat setempat selain sebagai fokus perhatian masyarakat juga dianggap sangat berkaitan erat dengan upacara sakral Marapu.

Dengan adanya Purungu Ta Kadonga Ratu pada masyarakat Anakalang sehingga menjadi adat kebiasaan atau menjadi tradisi orang Sumba artinya bahwa Upacara Adat Purungu Ta Kadonga Ratu akan menjadi nilai budaya masyarakat Anakalang yang merupakan suatu kebiasaan yang diturunkan dari para 
leluhur dari generasi-kegenerasi yang akan dipertahankan agar Upacara Adat Purungu Ta Kadonga Ratu, masyarakat Anakalang dapat menciptakan suatu keakraban dalam suatu kelompok masyarakat dan setiap budaya mengandung nilai sosiologis dalam kebudayaan tersebut.

Kepercayaan dan keyakinan adanya kekuatan gaib, yang melebihi kekuatan manusia biasa atau pengakuan atas wujud tertinggi, dituangkan dalam kepercayaan Marapu. Kepercayaan ini mengutamakan unsur-unsur kesucian, kebersihan jiwa, perdamaian, kerukunan, cinta kasih, keselarasan hubungan dan keseimbangan dunia akhirat, antara Tuhan dengan manusia, manusia dengan alam, kerukunan antara Kabihu/Marapu yang dipuja masing-masing Kabihu, serta dalam satu Kabihu. Kepercayaan marapu, adalah agama suku tradisional, yang berisi hukum dan ilmu suci bagi warga penganutnya, dalam wujud budaya dan religi.

Salah satu contoh budaya Sumba Tengah yang hingga kini masih berlangsung adalah upacara adat yang merupakan salah satu ritual adat yang bertujuan untuk memuja para arwah leluhur (ancestor worship), yang bersumber dari kepercayaan asli masyarakat Desa Makatakeri, Kecamatan Katikutana, Kabupaten Sumba Tengah yang dikenal dengan istilah Marapu. Marapu merupakan suatu kepercayaan kepada para leluhur, di mana Tuhan adalah pencipta langit dan bumi. Marapu bertumpuh pada pemujaan arwah nenek moyang dan meyakini roh leluhur sebagai penghubung antara mereka yang masih hidup dengan Sang Pencipta. Dalam kepercayaan Marapu, Tuhan disebut "'namawolu jeka namarawi" yang secara harafiah berarti yang membuat dan menciptakan. Penganut Marapu percaya adanya dewa-dewa yang hidup di sekeliling mereka.

Mereka juga percaya bahwa arwah nenek moyang yang telah meninggal dunia masih tetap hidup, sehingga mereka memperlakukan arwah nenek moyang secara istimewah. Perlakuan istimewah tersebut antara lain diwujudkan dalam bentuk pemberian sesajen melalui upacara-upacara atau ritual-ritual adat yang dipersembahkan pada roh leluhur. Salah satu bentuk upacara adat atau ritual adat yang hingga saat ini masih terus berlangsung adalah upacara adat Purung ta Kadonga Ratu (Turun di Lemba Imam) yang merupakan sebuah ritual yang bertujuan untuk meramalkan hasil pertanian dalam satu tahun berjalan. Purung Ta Kadonga Ratu (Turun di Lemba Imam) merupakan ritual adat yang dilakukan masyarakat Sumba setiap tahun sekali untuk memperingati para leluhur yang dianggap memiliki kekuatan magis dan dapat memprediksi kesuburan hasil pertanian masyarakat. Ritual adat Purung Ta Kadonga Ratu (Turun di Lemba Imam) sebelumdilaksanakan terlebih dahulu dilakukan acara pemotongan kerbau jantan yang bahasa adatnya "Haka Raja Rewa" yang artinya ukurantanduk kerbau yang akan dipotong untuk memberikan persembahan kepada leluhur. Acara ritual adat Purung ta Kadonga Ratu (Turun di Lemba Imam) di lakukan di sebuah tempat yang tinggi yang dirasa cocok oleh tua adat (“Ama Walu Adung, Ina Walu Kerung") yang dianggap sebagai kepala suku atau penanggung jawab untuk semua suku dalam melakukan ritual. Tempat dilakukan ritual adat 
Purung ta Kadonga Ratu (Turun di Lemba Imam) diberi nama "Laitarung".

Berdasarkan latar belakang diatas dalam penulisan ini di kajikan bagaimana orang sumba tengah mengontruksi ritual upacara adat Purung Ta Kadonga Ratu yang di anutnya yang berkaitan dengan keagamaannya, yaitu dengan mengungkapkan aspek-aspek yang berkaitan dengan ritual upacara adat Purung Ta Kadonga Ratu dan masyarakat desa makatakeri sumba tengah untuk memperoleh pemahaman tentang masyarakat desa makatakeri sumba tengah telah mempersiapkan ritual-ritual upacara adat Purung Ta Kadonga Ratu kepada orang-orang lain, dan bagaimana mereka menampilkan diri mereka kepada dunia luar. (Umbu pura 2007:31).

Ruang lingkup pembahasan menyangkut batasan tentang apa yang disebut ritual upacara adat Purung Ta Kadonga Ratu yaitu keyakinan segala aspek yang meliputi serta tata cara ibadahnya didasarkan pada aturan-aturan atau nilai-nilai pancasila yang berlaku dimasyarakat bersangkutan yang diwariskan secara turuntemurun dari nenek moyang mereka.

Melihat bahwa upacara adat Purung ta Kadonga Ratu (Turun di Lemba Imam) merupakan aturan-aturan atau nilai-nilai pancasila dan masyarakat pendukungnya menjadikan sebagai landasan yang kuat dalam keberlangsungan hidupnya, maka dipandang perlu untuk melakukan suatu pengkajian lebih lanjut melalui sebuah penelitian dengan judul: "Penerapan Nilai-Nilai Pancasila Dalam Pelaksanaan Upacara Adat Purung Ta Kadonga Ratu Pada Masyarakat Desa Makatakeri
Kecamatan Katikutana Kabupaten Sumba Tengah Provinsi Nusa Tenggara Timur".

\section{METODE}

Lokasi penelitian ini dilaksanakan di Desa Makatakeri Kecamatan Katikutana, Kabupaten Sumba Tengah Provinsi Nusa Tenggara Timur. Jenis penelitian ini adalah kualitatif. Dalam penelitian ini adalah mencari data mengenai gejala, fakta atau kejadian yang sudah terjadi yaitu mengenai Penerapan NilaiNilai Pancasila Dalam Pelaksanaan Upacara Adat Purung Ta Kadonga Ratu.

Teknik pengumulan data dalam penelitian ini menggunakan Teknik Observasi, Angket dan Dokumentsi. analisis yang digunakan adalah non statistik (kualitatif) untuk memperoleh suatu simpulan. Teknik yang digunakan dalam penelitian ini adalah metode deskriptif kualitatif. Data yang dikumpulkan dari teknik wawancara, tenik observasi, teknik dokumentasi, dideskripsikan sehingga mendapatkan kejelasan terhadap kenyataan.

\section{HASIL DAN PEMBAHASAN}

Sejarah Munculnya Upacara Adat Purung Ta Kadonga Ratu Pada Masyarakat Desa Makatakeri

Berdasarkan hasil wawancara dengan Umbu Datu Nyanyi, umur (72 tahun), pekerjaan petani dan beragama Marapu, pada tanggal 22 Mei 2019 mengatakan bahwa Upacara Purung ta Kadonga Ratu (Turun di Lemba Imam) sebagai proses alam yang diyakini dan diterima sebagai bagian dari perekat hubungan komunikasi dalam kehidupan masyarakat tradisional pada masa lampau hingga sekarang. 
Ikatan-ikatan upacara adat ini merupakan suatu pandangan sakral yang membentuk pola dan sikap atau perilaku serta pandangan kehidupan manusia dalam lingkungannya.

Upacara ini juga dianggap benar-benar tejadi dan diyakini kebenarannya serta disajikan dalam bentuk upacara suci. Upacara adat ini juga dikatakan mempunyai hubungan dengan sejarah atau asal mula suatu kejadian, tempat lahirnya suatu benda dan tokoh besar dalam sejarah tokoh sakti. Purung ta Kado nga Ratu (Turun di Lemba Imam) dikatakan sebagai upacara adat karena berasal dari suatu kisah 2 orang bersaudara yang dilahirkan dari keturunan nenek moyang Anakalang dimana kedua bersaudara sebagai anak dari bulan dan matahari yang memateraikan ritual Purung ta Kadonga Ratu (Turun di Lemba Imam) serta merupakan awal mula terjadinya tanaman padi di Analakalang yakni di atas sebuah batu kubur.

Anakalang berada di ibu kota Waibakul Kabupaten Sumba Tengah Propinsi Nusa Tenggara Timur. Di daerah ini terdapat suatu ritual adat warisan nenek moyang yang turun temurun masih tetap dilaksanakan sampai sekarang. Upacara adat Purung ta Kadonga Ratu (Turun di Lemba Imam) dijunjung tinggi oleh masyarakat setempat selain sebagai fokus perhatian masyarakat juga dianggap sangat berkaitan erat dengan upacara sakral Marapu.

Pelaksanaan upacara tersebut berasal dari cerita ribuan tahun silam tentang dua orang bersaudara dari Laitarung yang pergi ke Bali untuk mencari saudaranya dan memberitahukan kepada mereka kalau mereka sudah menemukan tempat tinggal yang cocok dan sudah beranak cucu di Laitarung, namun ternyata setelah bertahun-tahun pergi, mereka tidak kembali lagi ke Sumba sampai sekarang. Kepergian mereka yang tidak kunjung pulang membuat anak cucu mereka bersepakat untuk mengadakan suatu upacara adat sebagai tanda untuk mengenang dan meminta petunjuk kehidupan yang bagus dengan meminta berkat dari para leluhur untuk kesuburan hasil pertanian, Mehang Karaga menggambarkan fungsi pria sebagai kepala keluarga sementara Loda Pari menggambarkan fungsi wanita untuk mengatur dan menjaga tanaman padi sawah dan kebun agar menghasilkan dan terhindar dari serangga hama.

Upacara adat ini dilakukan dengan mengacungkan dua tombak pusaka keramat yang panjangnya kurang lebih 7 meter yang diacungkan ke langit untuk menjebol bendungan di langit untuk mendatangkan atau menurunkan hujan. Kedua tombak keramaat itu yakni Loda Pari dan Mehang Karaga. Apabila dalam lomba mengangkat tombak yang mengarah kelangit dan yang menang pertama adalah "Nibu loda pari" maka diprediksikan hasil pertanian subur dan musim hujan juga beraturan yang bahasa adatnya "hawewanaga pungina, kabobunaga ratina". Kalau "Nibu mehang karaga" yang menang pertama maka diprediksikan hasil pertanian tidak subur dan akan ada kelaparan besar melanda pulau Sumba yang bahasa adatnya "danakerimawaka tuwa danahimawaka watu, nyeka pagaliparawigika waiga bakukapata wewi wawi bakukanuka wewi kauki”.

Pelaksanaan Upacara Adat Purung ta Kadonga Ratu (Turun di Lemba Imam) 
Pelaksanaan Upacara Adat Purung ta Kadonga Ratu (Turun di Lemba Imam) adalah sebagai berikut:

Todu Kangurukungu-Bari Kanyakungu (Lobi untuk menyampaikan musyawarah dan setiap kabihu berunding untuk melaksanakan upacara Purung Ta Kadonga Ratu). Sebelum acara Purung ta Kadonga Ratu (Turun di Lemba Imam) dilaksanakan setiap kabisu harus mengganti ratu-ratu yang sudah meninggal, itu dilemparkan kepada setiap kabihu untuk mencari pengganti. Kelengkapan-kelengkapan dari seorang ratu harus di siapkan misalnya: emas-emas (amahu) pusaka yang harus dipakai oleh ratu, regi (kain) yang harus dipakai, rowa (ikat kepala), toda (taming), katopu (parang), kaleli wisi (rantai kaki), nibu (tombak). Waktu todu kangurukungu (Lobi untuk menyampaikan musyawarah) disampaikan, penobatan ratu yang baru sebagai pengganti ratu yang meninggal oleh setiap kabisu (dilakukan di Galubakul).

Uhi patti-paku tena (pembukaan resmi Upacara Adat Purung ta Kadonga Ratu). Uhi patti-paku tena dilaksanakan di Desa Makatakeri hari kedelapan setelah Todu Kangurukungu. Tahapan resmi, pembukaan resmi, dimana setiap kahisu melaporkan secara resmi serta bertanggungjawab mengenai jumlah ratu, kelengkapan ratu kepada Ratu Ina Ama (Ina patti tugga-Ama pamannu rasi). Kesimpulan dari uhi pati-paku tena ini kemudian ditentukan waktu untuk acara Batang pada hari yang keempat di Laitarung.

Upacara Batang di Laitarung. Pada hari yang keempat dilakukan upacara di depan rumah batang di Laitarung. Tempat upacara batang yang dilaksanakan disebut Kahali Rati
Batang. Upacara ini dipimpin oleh ratu dari Laimerang yang disebut Inna Ratu Bowu-Ma Bowa Lippa Newi, Ama Ratu Peka-Ma Peka Lii $\mathrm{Ka}$ Jalla, setelah sepakat maka mereka menentukan waktu 8 hari untuk acara Purung ta Kadonga Ratu (Turun di Lemba Imam).

Pakangu jara Upacara ini dilaksanakan pada hari keempat, dimana para ratu melakukan latihan Harama dan Negu (menari).

Pangudang (Pukul Gong). Upacara ini dilaksanakan pada hari kelima, dimana semua para ratu melaksanakan atau melakukan napak tilas dari Laitarung menuju Praiwona, dari Praiwona menuju Doku Watu (bermalam). Kemudian dari Doku Watu kembali ke Laitarung. Dari setiap kampung yang dilewati ratu pangudang memberikan pemberitahuan atau pengumuman akan dilaksanakannya Purung Ta Kadonga Ratu (Turun di Lemba Imam).

Susu malung yaitu tahapan terakhir dalam persiapan Purung ta Kadonga Ratu (Turun di Lemba Imam) dimana semua para ratu dan penganut kepercayaan pada malam ketujuh hadir di Laitarung untuk Negu Kawuku dan Taungu Lii. Pada saat Negu Kawuku dan Taungu Lii Ratu Ana Pinu Ladu-Anna Pinu Reja bertindak sebangai penyair dan pelagu di tengah Talora Pidu (Halaman Rumah Adat ). Pada malam hari sebelum susu malung dilaksanakan beberapa imam tertentu menimba air keramat untuk mengisi beberapa tempayan. Setelah tempayan-tempayan diisi dengan air maka para ratu ditiap kabisu naik ke kampung Laitarung sekitar pukul 23.00 karena kegiatan susu malungu dilakukan di Talora Pidu. 
Di Talora Pidu para ratu menari sebanyak 8 kali, kemudian disambung dengan Lodu (Menyanyi ) oleh ratu dari Kabelawuntu dimana Anna Pinnu Ladu-Anna Pinnu Reja, sebagai penyair dan pelagu. Selanjutnya dilanjutkan dengan Taungu Lii (tutur adat) dimana masing-masing kabihu melakukan Taungu Lii (tutur adat) sebanyak 3 kali. Sekitar jam 05.00 pagi para kabisu bubar dan kembali ke tempat masing-masing untuk istirahat sambil menunggu acara puncak Purung Ta Kadonga Ratu (Turun di Lemba Imam) pada siang hari.

Puncak acara Purung ta Kadonga Ratu (Turun di Lemba Imam) dilaksanakan di arena Kadonga Ratu dengan mengacungkan dua tombak pusaka keramat yang panjangnya kurang lebih 7 meter ke langit sebanyak 4 kali. Setiap dua kali tombak diacungkan menandakan satu kali pertemuan. Dua tombak pusaka tersebut yakni Loda Pari dan Mehang Karaga. Untuk menentukan tombak mana yang menang ada beberapa ratu khusus sebagai juri (penentu) kalah atau menang. Ratu-ratu tersebut hanya duduk membisu tapi pandangan terpusat selama kegiatan tersebut dilaksanakan. Ratu-ratu ini disebut dengan istilah Ratu Hanguja.

Wadah atau Media yang di Gunakan meliputi: (1) Media yang khusus atau yang paling di sakralkan adalah lemba imam (kadonga) adalah sebagai tempat pemohon restu dari nenek moyang atau dewa marapu. (2) Tombak (nibbu) yang harus di pertarungkan pada saat kegiatan berlangsung yang di pegang oleh kedua belah suku yaitu nibbu loda pari (tombak) dan nibbu mehang karaga. (3) Kain (regi) parang (katopu) tas siri pinang (karera pamama) ikat kepala (rowa) taming (toda) emas (mamuliamah) gelang kaki (kaleli wihi) ini adalah sebuah perlengkapan yang harus di pakai oleh tua adat pada saat melaksanakan upacara adat purung taka donga ratu.

Nilai-nilai Pancasila yang terkandung dalam upacara adat Purung Ta Kadonga Ratu yang di laksanakan di desa makatakeri

\section{Nilai Kebersamaan}

Budaya merupakan suatu cara hidup yang berkembang dan dimiliki bersama oleh sekelompok orang yang diwariskan secara turun temurun dari genersai kegenerasi. Sebagaimana juga budaya tidak dipisahkan dari diri manusia sehingga banyak orang cenderung menganggapnya sebagai warisan secara genetis. Kebudayaan sangat erat hubungannya dengan masyarakat bahwa segala sesuatu yang terdapat dalam masyarakat ditentukan oleh kebudayaaan yang dimiliki oleh masyarkat itu sendiri

Kebersamaan yang baik adalah kebersamaan yang terbentuk karena kebutuhan (need) bukan dipaksakan. Kebersamaan yang terbentuk karena kebutuhan biasanya lebih mudah mencapai tujuan di banding bila kebersamaan terbentuk karena di paksakan, atau memiliki hambatan yang cukup besar dalam upaya, pencapaian tujuan. Untuk menjalin kerja sama dan keharmonisan diperlukan ketulusan hati dan kehalusan jiwa. Dari jiwa yang halus akan mengurangi sifat-sifat yang kasar. Kehalusan budi merupakan pedoman untuk mendapatkan rasa kebersamaan. Pendidikan keindahan ,kebersamaan yang bersifat relegius adalah sebagai alat perakat untuk menumbuhkan rasa kasih sayang, membangun jiwa dengan sikap yang lembut sehingga perilaku masyarakat menjadi lebih tenang, damai dan pada akhirnya 
akan dapat melaksanakan berpikir, berkata dan berbuat atas dasar kesadaran budi dengan daya nalar yang rasional.

Hubungan dengan Upacara Adat Purung Ta Kadonga Ratu adalah pada saat akan melaksanakan Upacara Adat Purung $\mathrm{Ta}$ Kadonga Ratu para Ratu yang terdiri dari warga setempat secara bersama-sama dan saling bahumembahu dalam melaksanakan pakabuangu pata mbokul (Bicara Rapat musyawarah dan bersepakat bersama di dalam forum / untuk mengambil keputusan). Sehingga timbul rasa kebersamaan dan persatuan antara sesama warga. (Dimas P. Umbu B. Tagukoda), wawancara tanggal 21 Mei 2019).

\section{Nilai Keikhlasan}

Masyarakat Desa makatakeri sebelum melakukan upacara adat purung ta kadonga ratu merekah adakan melaksanakan pakabuangu pata mbokul (rapat musyawarah dan bersepakat bersama di dalam forum / untuk mengambil keputusan). Masyarakat Desa makatakeri dengan iklas menyerahkan upacara adat purung ta kadonga ratu samapai upacara itu benarbenar selesai.

\section{Nilai persaudaraan}

Adalah terjalinnya suatu hubungan timbal-balik antara individu yang satu dengan lainnya yang terikat oleh rasa kebersamaan, saling menyayangi, mengasihi, saling memberi dan menerima. Dengan adanya Upacara Adat Purung Ta Kadonga Ratu semua orang dari berbagai penjuru berkumpul di Desa Makatakeri tiada rasa persaingan, tiada perbedaan ras, apalagi orang yang beriman. Semua dianggap keluarga, dalam pelaksanaan upacara Purung Ta Kadonga Ratu.
Nilai-Nilai Pancasila Dalam Upacara Adat Purung TaKadonga Ratu

Sila pertama mengandung Nilai Ketuhanan Yang Maha Esa meliputi seluruh hidup kebatinan manusia, sehingga segala bentuk aliran keagamaan dan kepercayaan di bulatkan menjadi satu dan di tunjukkan kepada suatu bentuk kepercayaan kepada Tuhan Yang Maha Esa. Esa artinya satu, tiada duanya karena Tuhan yang disembah oleh sebagai ras dan suku bangsa sesuai dengan kepercayaan dan agamanya serta menurut bahasanya memeng hanya satu. Dalam Upacara Adat Purung Ta Kadonga Ratu juga terkandung nilai-nilai sila pertama pancasila, yaitu Ketuhanan Yang Maha Esa. nilai itu tercermin ketika para masyarakat desa makatakeri melakukan persembahyangan bersama sebelum "Upacara Adat Purung Ta Kadonga Ratu" dimulai untuk memohon keselamatan dan kelancaran dalam menjalankan Upacara Adat Purung Ta Kadonga Ratu

Sila Kedua mencerminkan Nilai kemanusiaan keunikan eksistensi manusia di lukiskan oleh notonegoro sebagai monopluralisme, yang mencakup mono-dualisme susunan kodrat (individu-sosial) dan mono dualism kedudukan kodrat (pribadi mandiri makhluk Tuhan). sesuai dengan manusia sebagai makhluk sosial maka tidak ada manusia yang biasa hidup menyendiri secara permanen. nilai-nilai sila kedua pancasila juga terkandung dalam Upacara Adat Purung Ta Kadonga Ratu. Nilai tampak ketika para masyarakat sekitar membantu rekan-rekannya yang membutuhkan pertolongan yang berkaitan dengan Upacara Adat Purung Ta Kadonga Ratu 
Sila ketiga mengandung nilai persatuan. Persatuan berasal dari kata satu yang berarti utuh dan tidak terpecah-pecah. Jadi, persatuan artinya wujud keutuhan yang dibentuk melalui proses persatuan dari berbagai corak dan unsur yang beranekaragam "Menurut Ernest Renan eksistensi bangsa itu ditemukan oleh adanya kehendak bersatu, mempuyai jiwa,dan solidaritas yang besar, dalam Upacara Adat purung ta kadonga ratu di Desa Makatakeri juga terkandung nilai persatuan yaitu tidak adanya rasa permusuhan dan dendam diantara keluarga.

Sila keempat ini mencerminkan nilai demokrasi atau kerakyatan. indonesia memiliki tradisi yang oleh Moh.Hatta di sebut didemokrasi asli. inti dari demokrasi ini adalah musyawarah dan masyarakat dimana roda organisasi dijalankan dengan nasihat dan bantuan semua penduduk yang dianggap sudah tua atau dewasa dalam menghadapi segala keperluan umum dan pengambilan keputusan dilakukan secara musyawarah. Dalam perkembangan selanjutnya muncul demokrasi tidak langsung yakni melalui lembaga perwakilan. nilai sila keempat pancasila yaitu kerakyatan yang dipimpin oleh hikmat kebijaksanaan dalam permusyawaratan/ perwakilan juga terkandung dalam Upacara Adat Purung Ta Kadonga Ratu di Desa Makatakeri. Nilai ini tercermindalam penentuan kelompok bersatu dalam acara Purung Ta Kadonga Ratu kelompok masyarakat yang dinyatakan bersatu dalam acara tidak dapat di ganggu gugat keputusan oleh kelompok yang sedang melakukan acara merupakan aturan atau kesepakatan bersama yang menyatakan kelompok masyarakat.

Sila kelima mengandung keadilan. keadilan dapat didefenisikan sebagai kehendak untuk memberikan apa yang menjadi hak dan bagian seorang berdasarkan atas kesamaderajatan manusia dan perbedaan manusia. Nilai ini tercermin dalam penentuan ratu masyarakat sumba tengah harus benerbener sepakat apabila masyarakat sumba tengah melanggar aturan ini maka Upacara Adat Purung Ta Kadonga Ratu akan di tunda.

\section{Nilai Kemanusian Dalam Upacara Adat} Purung Ta Kadonga Ratu

Nilai kemanusian adalah perhimpunan untuk membahas bersama masalah-masalah yang dihadapi untuk mendapatkan kesimpulan yang di setujui bersama dan menjadi keputusan bersama. Masyarakat Sumba pada umumnya sangat menghormati keputusan-keputusan yang diambil berdasarkan musyawarah, dimana tokohnya atau yang mewakili turut hadir dan memberikan pendapat. pertemuan itu disebut pakabuangu pata mbokul (rapat musyawarah dan bersepakat bersama di dalam forum / untuk mengambil keputusan).

Menurut nara sumber Agustinus $\mathbf{J}$ Sobang pada tanggal 24 Mei 2019 mengatakan bahwa Upacara Adat Purung Ta Kadonga Ratu perlu di ingat karena akan di adakan musywarah sebelum acara adat/ritual Purung $\mathrm{Ta}$ Kadonga Ratu berlangsung dan musyarawarah ini adalah nilai-nilai yang sangat penting dalam kegiatan Purung Ta Kadonga untuk meminta persetujuan dengan para lelulur, sehingga keputusan ini bersifat sacral. Selesai musyawarah langsung dilakukan dua hal 
penting, yaitu, pertama: Panewi Dangaja Damarapu (tata cara untuk berkomunikasi para leluhur) dan yang kedua, koja atau tebung (memberikan persembahan).

\section{Tujuan Dari Purung Ta Kadonga ratu (Turun} di Lembah Iman)

Tujuan purung ta kadonga ratu ini bertujuan untuk meminta berkat Hujan dari para leluhur mereka sehingga tanaman padi mereka tidak kerimg sehingga tidak menderita keleparan. Pada perayaan ini, ada 2 tombak yang digunakan yaitu Mehang Karaga dan Loda Pari. Mehang karaga adalah simbol pria dan Loda Pari adalah symbol wanita. Tombak tersebut mempunyai panjang kurang lebih 7 meter. Kedua tombak ini mempunyai fungsi dan aturannya sendiri. Mehang Karaga menggambarkan fungsi pria sebagai kepala keluarga sementara Loda Pari menggambarkan fungsi seorang wanita yang mempunyai kewajiban untuk mengatur dan menjaga dengan baik hasil panen yang diperoleh dari sawah maupun dari kebun.

Upacara adat Purung Ta Kadonga ratu di daerah ini sangat sakral sehingga di jalankan setiap tahun. Upacara adat yang masih dijumpai dalam masyarakat ini adalah memberikan korban bakaran, memohon berkat dan rahmat, melindungi para penganutnya dari bahaya agar usaha pertanian, peternakan dan kehidupan berhasil.

Kepercayaan atau keyakinan adanya kekuatan gaib yang melebihi kekuatan manusia biasa atau pengakuan akan wujud tertinggi yang di tuangkan dalam kepercayaan atau keyakinan Marapu yang di percayai oleh masyarakat sekitar. Kepercayaan ini diwujudkan dalam bentuk batu yang di puja oleh masing-masing suku (kabihu). Dalam kabisu atau suku kepercayaan Marapu adalah suku tradisional yang berisi hukum dan ilmu suci bagi warga penganutnya dalam wujud budaya. Upacara di daerah ini sangat sakral sehingga dijalankan setiap tahun sekali. Upacara adat yang masih di ju mpai saat ini dalam masyarakat Anakalang adalah memohon berkat dan rahmat untuk kesuburan hasil pertanian, untuk kehidupan yang bagus serta memberikan korban bakaran atau sesajen kepada para leluhur yang di anggap memiliki kekuatan gaib.

Dalam kaitannya dengan lembaga adat maka kabisu - kabisu atau suku-suku di bagi dalam empat suku atau kabihu besar yaitu : (1) Kabihu doku gawi, (2) Kabihu nuku sara, (3) Kabihu kabelawuntu, (4) Kabihu matolang , Korubeba, taupopu, anabura, (ina walu kerung ama walu adung) sebagai pengendali keamanan dan kesejahteraan.

\section{PENUTUP}

Setelah penulis menguraikan serta menganalisis bab demi bab dari keseluruhan uraian tersebut diatas mengenai Penerapan Nilai - Nilai Pancasila dalam Pelaksanaan Upacara Adat Purung Ta Kadonga Ratu Pada Masyarakat Desa Makatakeri, Kecamatan Katikutana, Kabupaten Sumba Tengah, Provinsi Nusa Tenggara Timur ; maka berikut ini penulis menyajikan beberapa simpulan dan saran.

Nilai-nilai pancasila yang terkandung dalam setiap pancasila sebagai dasar Negara dan ideologi yang mengandung nilai-nilai yang dijadikan pedoman bagi bangsa Indonesia dalam kehidupan bermasyarakat berbangsa dan 
bernegara adalah sebagai berikut: (1) Sila pertama yakni'Ketuhanan Yang Maha Esa" mengandung pengertian bahwa bangsa Indonesia mempunyai kebebasan untuk menganut agama dan menjalankan ibadah yang sesuai dengan ajaran agamanya. Sila pertama ini juga mengajak manusia Indonesia untuk mewujudkan kehidupan yang selaras, serasi dan seimbang antar sesama warga Negara Indonesia, maupun dengan makhluk Tuhanyang lainnya. Dengan demikian,di dalam jiwa bangsa Indonesia akan timbul rasa saling menyayangi, menghargai, dan mengayomi. (2) Kemanusia Yang Adil Dan Beradab Mengandung pengertian bahwa bangsa Indonesia diakui dan diperlakukan sesuai dengan harkat dan martabatnya selaku makhluk Tuhan Yang Maha Esa, yang sama derajatnya, sama hak dan kewajibannya. (3) "Persatuan Indonesia" dalam sila ketiga pancasila adalah suatu wujud kebulatan ipoleksosbudhankam dalam berbagai aspek kehidupan, yang meliputi ideologi, politik, ekonomi, sosial, budaya, dan pertahanan keamanan yang semuanya terwujud dalam suatu wadah, yaitu Indonesia. (4) Kerakyatan Yang Dipimpin Oleh Hikmat Kebijaksanaan Dalam Permusyawaratan/Perwakilan. Setiap orang Indonesia sebagai warga masyarakat, bangsa dan Negara mempunyai hak, kewajiban, dan kedudukan yang sama dalam pemerintahan.karena itu, setiap kegiatan pengambilan keputusan yang menyangkut kepentingan bersama terlebih dahulu selalu mengadakan musyawarah untuk mencapai mufakat. Musyawarah untuk mencapai mufakat tersebut dilakukan dengan semangat kekeluargaan sebagai ciri khas kepribadian bangsa Indonesia. (5) Keadilan Sosial Bagi Seluruh Rakyat Indonesia, Bersikap adil terhadap sesame, Menghormati hak-hak orang lain, Menolong sesame dan Menghargai orang lain.

Proses pelaksanaan Upacara Purung Ta Kadonga Ratu oleh masyarakat Sumba Tengah, Desa Makatakeri yang harus dilakukan dan ditaati olegh setiap warga setempat bagi yang beragama marapu. (1) Todu Kangurukungu-Bari Kanyakungu (Lobi untuk menyampaikan musyawarah dan setiap kabihu berunding untuk melaksanakan upacara Purung Ta Kadonga Ratu). (2)Uhi patti-paku tena (pembukaan resmi Upacara Adat Purung ta Kadonga Ratu), (3) Upacara Batang di Laitarung. Pada hari yang keempat dilakukan upacara di depan rumah batang di Laitarung. Tempat upacara batang yang dilaksanakan disebut Kahali Rati Batang. (4) Pakangu jara, Upacara ini dilaksanakan pada hari keempat, dimana para ratu melakukan latihan Harama dan Negu (menari). (6) Pangudang (Pukul Gong), Upacara ini dilaksanakan pada hari kelima, dimana semua para ratu melaksanakan atau melakukan napak tilas dari Laitarung menuju Praiwona, mengelilingi kampung yang dilewati ratu pangudang memberikan pemberitahuan atau pengumuman akan dilaksanakannya Purung $\mathrm{Ta}$ Kadonga Ratu (Turun di Lemba Imam). (7) Susu malung yaitu tahapan terakhir dalam persiapan Purung ta Kadonga Ratu (Turun di Lemba Imam) dimana semua para Ratu dan penganut kepercayaan pada malam ketujuh hadir di Laitarung untuk Negu Kawuku dan Taungu Lii. 


\section{DAFTAR PUSTAKA}

Djajasudharma, T Fatim. 2010. Sumantik 1. Pengantar Kearah Ilmu Makna. Jakarta: Balai Pustaka.

Endraswara, Suwardi. 2008. Metodologi Penelitian Sastra. Yogyakarta: Media Presindo.

Hardjasoemantari, Koesnadi. 2000:558 Nilainilai Pancasila dan undang-undang No. 23 Tahun 1997.Jakarta

Kartika, I Made \& Mahendra, Putu Ronny Angga. Tri Hita Karana Sebagai Landasan Mewujudkan Kepemimpinan Pancasila. Universitas Dwijendra Denpasar : Prosiding Seminar Nasional Inovasi dalam Penelitian Sains, Teknologi dan Humaniora - InoBali 2019 hal $222-228$.

Koentjaraningrat. 1997. Pengatar Ilmu Antropologi Jilid II. Rineka Cipta, Jakarta.

Mahendra, Putu Ronny Angga. Sistem Pembagian Tanah Ulayat pada Masyarakat Manggarai Suku Langkat Kelurahan Carep Kecamatan Langke Tembong Kabupaten Manggarai (Tinjauan Nilai-Nilai Pancasila). Jurnal Pendidikan Kewarganegaraan Undiksha Vol.8 No.1 Tahun 2020 hal 106 - 112.

Mahendra, Putu Ronny Angga. Civic Culture Ngayah Dalam Pembelajaran PPKn. AP3KnI Jateng: Jurnal PPKn Vol. 6 No. 1 Januari 2018.

Nazir, Muhammad. 1985. Metodologi. Jakarta: PT. Gajah Mada University Press.

SJ. Susanto, Budi. 1992. Kebudayaan dan Agama. Yogyakarta: Penerbit Kanisius.

Sugiyono. 2012 Metode Penelitian Kuantitatif, Kualitatif Dan Rdd. Cetakan Ke 17. Bandung: Alfabeta Hal 31

Soeriandiedja, P. 2004 Marapu : Agama Asli Orang Sumba Dalam Budaya Sana-Sini. Denpasar: Laban-FS UNUD

Wellem. F. Dj. 2014. Injil dan Marapu.BPK. Gunung Mulia. Jakarta.

Sukardi. 2017. Metodologi Penelitian Pendidikan. Jakarta: PT. Aksara 